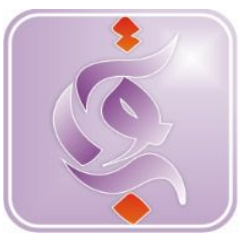

\title{
KEPEMIMPINAN OTENTIK DALAM ORGANISASI
}

Received: $28^{\text {th }}$ March 2019; Revised: $13^{\text {th }}$ April 2019; Accepted: $26^{\text {th }}$ April 2019

\author{
Winbaktianur \\ Universitas Islam Negeri Imam Bonjol \\ Padang \\ Email: winbaktianur@uinib.ac.id \\ Sutono \\ Universitas Islam Negeri Imam Bonjol \\ Padang \\ Email: sutono1968@yahoo.co.id
}

\begin{abstract}
The purpose of this study is to explain the concept of authentic leadership. Authentic leadership includes something that has growing rapidly in the last two decades, and it is interesting to discuss. Authentic leadership as a pattern of leader behavior that utilizes and enhances positive psychological capacity and a positive ethical climate, to foster greater self-awareness, internalized moral perspective, balanced information processing, and relational transparency from leaders who work with followers, encourage positive self-development. In its implementation authentic leadership is a leader who is able to be honest with himself and followers. Authentic leaders must be aware of themselves and be able to foster self-awareness of their employees to work optimally in the organization.
\end{abstract}

Keywords: authentic leadership, organization

\section{PENDAHULUAN}

Istilah pemimpin adalah hal yang sangat sering didengungkan, hal ini dikarenakan hampir semua di dunia ini bersinggungan dengan pemimpin dan memerlukan pemimpin. Sehingga dapat dikatakan pemimpin adalah hal yang sangat vital dalam kehidupan manusia. Seorang pemimpin memastikan suatu kegiatan atau program berjalan dengan baik karena pemimpin yang mengendalikan, mendorong serta menggerakkan untuk bersama-sama melaksanakan program itu.

Mengutipdari Andiyasari \&Pitaloka (2017) kepemimpinan otentik muncul sebagai perspektif alternatif kepemimpinan dalam berbagai organisasi termasuk lingkungan pendidikan (Bhindi \& Duignan, 1997 dalam Smith, Bhind, Hansen, Riley, Dan \& Rall,Johan, 2008). Tipe kepemimpinan ini diyakini dapat memberikan perbedaan fundamental dalam organisasi untuk membantu individu menemukan makna dalam bekerja melalui self-awareness. Sebuah kesadaran yang bersumber dari keyakinan dan harapan, mengutamakan keterbukaan dalam interaksi dan proses pengambilan keputusan yang berujung pada pembentukan rasa percaya, komitmen dan persepsi etika di antara pengikut(Avolio, Gardner, Walumbwa, Luthans, \& May, 2004 dalam Lagan, 2007) Teori kepemimpinan otentik mengandung kapasitas psikologi positif berupa keyakinan diri, optimisme, harapan dan resiliensi sebagai kekuatan utama seorang pemimpin. Kapasitas inilah yang akan memprediksi tingkat self-awareness dan self-regulatory pada tindakan pemimpin (Lagan, 2007). Tidak hanya kapasitas psikologis, teori kepemimpinan otentik juga melibatkan konteks organisasi sebagai fasilitator hubungan antara kepemimpinan otentik dan performa yang muncul (Avolio \& Gardner, 2005). Kapasitas psikologis tersebut akan tercapai dalam konteks organisasi yang positif (Lagan, 2007). 
Seorang pemimpin tidak terlepas dari cara memimpin atau biasa disebut dengan kepemimpinan. Terdapat beragam kepemimpinan yang dapat dijumpai, namun satu di antaranya adalah kepemimpinan otentik. Kepemimpinan otentik mulai banyak mendapat perhatian para peneliti sejak dua dekade ini, walaupun sebenarnya beberapa penelitian telah dimulai pada beberapa dekade sebelumnya. Awal perkembangannya, konsep kepemimpinan otentik ini dikaji dalam lingkup sosiologi dan pendidikan. Tercatat misalnya penelitian yang dilakukan oleh seorang sosiolog, Seeman (1966), ia mengkaji tentang konsep inauthenticity. Kemudian di tahun 1983, penelitian dengan konsep yang sama dilakukan oleh Henderson dan Hoy dalam bidang pendidikan namun dengan menambah beberapa aitem baru pada skalanya, (dalam Budiharto).

Berdasarkan hasil kajian-kajian peneliti yang telah dilakukan selama dua dekade ini, memperlihatkan hasil bahwa kepemimpinan otentik diketahui memberikan pengaruh positif terhadap kinerja organisasi. Di antaranya memperlihatkan pengaruh positif kepemimpinan otentik juga diketahui dalam meningkatkan perilaku positif, menurunkan perilaku negatif pemimpin dan pengikut sebagai individu maupun kelompok dalam organisasi. Juga dapat meningkatkan perilaku positif dalam organisasi, karena terbukti berpengaruh positif terhadap kepuasan dalam bekerja, perilaku kewargaan, keterpikatan kerja, komitmen; serta kebahagiaan. Selain itu juga dapat dimaknai menurunkan perilaku negatif dalam organisasi, sepertiburn out,stres karyawan, emotional exhaustion, cynicism, organizational deviance, absence frequency, dan turnover intentions.

Kepemimpinan otentik menurut Alvolio, Gardner, dan Walumbwa (2005) adalah pendekatan terhadap kepemimpinan yang menekankan pentingnya membangun legitimasi pemimpin melalui hubungan yang jujur dengan pengikut, yang menghargai masukan mereka, dan dibangun di atas landasan etika. Kemudian definisi kepemimpinan otentik kembali dikemukakan oleh Walumbwa et al. (2008:94), sebagai pola perilaku pemimpin yang memanfaatkan dan meningkatkan kapasitas psikologis positif dan iklim etis yang positif, untuk mendorong kesadaran diri yang lebih besar, perspektif moral yang diinternalisasi, pemrosesan informasi yang seimbang, dan transparansi relasional dari para pemimpin yang bekerja dengan pengikut, mendorong pengembangan diri yang positif.

Pentingnya peran pemimpin dalam organisasi membuat kepemimpinan menarik untuk dibahas, maka dalam artikel ini penulis akan mengulas tentang kepemimpinan otentik. Selain itu, kepemimpinan otentik belum banyak ditulis dalam bahasa Indonesia. Artikel ini akan membahas kepemimpinan otentik dalam organisasi dimulai dari defenisi kepemimpinan otentik, karakteristik kepemimpinan otentik dan dimensi-dimensi kepemimpinan otentik.

\section{Definisi Kepemimpinan Otentik}

Kepemimpinan otentik terdiri dari dua kata, yaitu kepemimpinan dan otentik. Dalam kamus Besar bahasa Indonesia, otentik berarti dapat dipercaya, asli, tulen, sah. Kepemimpinan diartikan sebagai kemampuan untuk mempengaruhi perilaku seseorang atau kelompok orang untuk mencapai tujuan tertentu dan situasi tertentu. Apabila dirujuk kepada bahasa Inggris, kepemimpinan disebut dengan leadership, menurut Yukl (2015), memiliki makna kemampuan dan proses mempengaruhi orang lain untuk mencapai tujuan tertentu. Untuk istilah otentik (authenticity) berasal dari istilah Yunani, yaitu "Authento" (to have full power), yang memiliki makna otentik (Gardner, Cogliser, Davis, \& Dickens, 2011).

Shamir dan Eilam (2005) mendefinisikan pemimpin otentik sebagai orang yang memiliki pengetahuan diri dan kejelasan konsep diri. Pendapat lainnya dikemukakan oleh Avolio, Luthans, \& 
Walumbwa (2004) mendefinisikan pemimpin otentik sebagai pemimpin yang sangat sadar terhadap dirinya (deeply aware) dalam berpikir dan bertindak, serta dipersepsi orang lain sebagai orang yang sadar terhadap nilai-nilai moral dirinya dan orang lain; berwawasan luas dan memiliki kekuatan; sadar konteks di mana sedang berada; merasa yakin, memiliki harapan, optimisme, ketangguhan, dan karakter moral yang tinggi. Pemimpin otentik merasa yakin, memiliki harapan, optimis, tangguh, transparan, bermoral, berorientasi masa depan, dan memberikan prioritas untuk mengembangkan pengikutnya menjadi pemimpin, minimal bagi dirinya sendiri.

Ilies dkk. (2005) menjelaskan bahwa pemimpin otentik sangat menyadari nilai hidup dan keyakinannya, percaya diri, asli (genuine), dapat diandalkan dan dipercaya, fokus pada pengembangan kekuatan para pengikutnya, memperluas pemikiran pengikutnya, dan menciptakan suasana organisasi yang positif dan menyenangkan.

Sedangkan Jensen dan Luthans (2006) mendefenisikan kepemimpinan otentik sebagai kemampuan untuk memproses kapasitas psikologi positif dalam konteks perkembangan organisasi yang menghasilkan kesadaran diri, perilaku positif, regulasi diri yang tinggi pada pemimpin dan pengikutnya serta membantu pengembangan diri yang lebih positif. Yukl (2015) menyatakan bahwa nilai inti dari kepemimpinan otentik yaitu memotivasi mereka sendiri untuk melakukan apa yang benar dan adil bagi pengikut, menciptakan jenis hubungan dengan pengikut yang mencakup rasa saling percaya yang tinggi, komunikasi terbuka dan jujur, memiliki tujuan bersama yang bernilai positif. Avolio dan Gardner (2005) mendefinisikan kepemimpinan otentik sebagai pemimpin yang memiliki kesadaran diri yang tinggi dalam berfikir serta bertindak dan orang lain mempersepsikan pemimpin tersebut memiliki kesadaran tentang nilai moral dirinya dan orang lain, memiliki pengetahuan yang luas dan kekuatan, sadar apa yang sedang dilakukan oleh dirinya, percaya diri, optimisme, tangguh dan memiliki kesadaran moral.

Definisi kepemimpinan otentik yang banyak menjadi rujukan adalah oleh Walumbwa et al. (2008:94) mendefinisikan kepemimpinan otentik sebagai pola perilaku pemimpin yang memanfaatkan dan meningkatkan kapasitas psikologis positif dan iklim etis yang positif, untuk mendorong kesadaran diri yang lebih besar, perspektif moral yang diinternalisasi, pemrosesan informasi yang seimbang, dan transparansi relasional dari para pemimpin yang bekerja dengan pengikut, mendorong pengembangan diri yang positif.

$$
\text { Hassan dan Ahmed }
$$

menyatakan bahwa authentic leadership mampu menciptakan kepercayaan interpersonal pegawai terhadap atasan, yang kemudian meningkatkan level of engagement atau keterikatan pegawai dengan organisasi.

\section{Karakteristik Kepemimpinan Otentik}

Mengutip Kruse (2013), terdapat beberapa konsep kepemimpinan otentik dengan karakteristik sebagai berikut;

1. Authentic leaders are self-aware and genuine. Pemimpin-pemimpin yang otentik adalah individu yang mengaktualisasikan dirinya dengan memilikiself-awareness (kesadaran diri). Mereka mengetahui kekuatan dan kelemahan pada diri mereka sendiri dan emosi mereka. mereka juga tidak berperilaku berbeda di berbagai kondisi, dengan kata lain mereka menjadi diri mereka di hadapan para pengikutnya. Mereka juga tidak takut untuk terlihat lemah dengan mengakui kesalahankesalahan yang pernah dilakukan dan kegagalan yang pernah mereka lalui.

2. Authentic leaders are mission driven and focused on results. Mereka mampu menempatkan misi-misi untuk mencapai tujuan orang banyak atau organisasi di atas tujuan pribadi. Mereka melakukan pekerjaan mereka untuk mencapai hasil bukan untuk 
kekuasaan, ego dan keinginan materi pribadi.

3. Authentic leaders lead with their heart. Mereka tidak takut untuk menunjukkan emosi-emosi yang mereka miliki, kerentanan mereka terhadap karyawan. Namun bukan berarti mereka "lembek", akan tetapi dapat mengkomunikasikan apa yang dirasakan dengan tata cara yang tepat beserta empati.

4. Authentic leaders focus on the longterm. Mereka fokus untuk hasil jangka panjang, bersedia untuk membimbing setiap orang dan memelihara organisasi dengan sabar dan kerja keras karena mereka yakin dengan hasil yang akan bertahan untuk jangka waktu yang lama.

Karakteristik berikutnya dijelaskan oleh Shamir dan Eilam (2005), Pertama, pemimpin otentiktidak menjalankan sebuah kepemimpinan yang palsu. Merekatidak berpura-pura menjadi pemimpin hanya karena berada dalam posisi kepemimpinan tertentu. Dengan kata lain, ketika menjalankan peran kepemimpinan, pemimpin otentik menjadi diri sendiri. Kedua, pemimpin otentik tidak mengambil peran kepemimpinan demi status, kehormatan, atau penghargaan pribadi lainnya. Sebaliknya, mereka memimpin dengan misi dan keyakinan. Mereka memiliki nilai-nilai dasar yang ingin dipromosikan agar bisa membuat perbedaan. Ketiga, proses yang dialami seorang pemimpin otentik untuk sampai pada keyakinan, nilai-nilai, misi, atau pemicu kepemimpinannya itu bukan imitasi. Keyakinan, nilai-nilai,atau misi tersebut mungkin saja mirip dengan konsep yang diajukan pemimpin lain. Tapi, seorang pemimpin otentik, mendapatkan semua itu melalui refleksi dari pengalaman pribadinya sendiri. Keempat, pemimpin otentik selalu berbicara dan bertindak berdasarkan nilainilai dan keyakinannya. Bukan untuk menyenangkan "penonton", mendapatkan popularitas, atau didorong oleh kepentingan politik yang sempit. Karena terdapat konsistensi antara nilai dan keyakinan dengan pernyataan dan tindakan, pemimpin otentik memiliki tingkat integritas personal yang tinggi.

Margarito Mayo dalam Munir (2018) menjelaskan karakteristik kepemimpinan otentik dan proses pembentukannya, sebagai $3 H$ dari kepemimpinan otentik: Heart, Habit, dan Harmony. Komponen Heart atau hati dalam kepemimpinan otentik berarti otentik secara emosional (emotional authenticity). Pemimpin otentik jujur pada diri sendiri be true to yourself. Lihat ke dalam diri sendiri dan menemukan apa yang menjadi gairah atau passion. Jadi kalau maju sebagai kandidat kepala daerah, harus jujur pada diri sendiri, apa yang membuat kandidat tersebut berambisi menjadi bupati, walikota, atau gubernur. Gairah itulah yang menjadi magnet yang memengaruhi dan menggerakkan para pengikut yang memiliki passion yang sama.

Komponen Habit atau kebiasaan dalam kepemimpinan otentik secara spesifik merujuk pada kebiasaan belajar. Melalui belajar, manusia akan mengubah dirinya menjadi lebih efektif dalam menghadapi lingkungan. Pemimpin otentik mempunyai kebiasaan belajar melalui umpan balik yang jujur. Kalau dikritik, pemimpin otentik bersedia mendengarkan, bukan ngamuk, bicara kasar, menggunakan power untuk menekan, menteror, bahkan membungkam. Pemimpin otentik mengembangkan mindset bertumbuh. Umpan balik yang kritis membuatnya belajar agar mampu beradaptasi, bertumbuh, dan terus maju - be true to your best self.

Komponen Harmony dalam kepemimpinan otentik terkait dengan lingkungan, atau dalam hal ini, pengikut. Pemimpin otentik perlu mencari keseimbangan. Dia konsisten mencapai tujuan, target, tapi juga menimbang kenyataan praktis (down-to-earth). Dia punya prinsip, konsisten dengan nilai-nilai yang dipegangnya, namun tetap sadar bahwa hidup, bekerja dengan orang lain, serta komunitas yang lebih luas. Pemimpin otentik membangun harmoni antara dirinya dan pengikut atau stake holders, dengan 
tujuan membangun konteks bersama yang otentik. Masyarakat atau rakyat itu, walau mungkin memilih hanya karena menjalankan kewajiban sebagai warganegara tanpa tahu persis siapa kandidat-kandidatnya, masing-masing memiliki harapan agar kabupaten, kota, atau propinsi dimana ia tinggal atau bekerja menjadi lebih kondusif. Konteks bersama yang otentik itu adalah pertemuan antara harapan konstituen dan janji kandidat - be true to others.

\section{Indikator Kepemimpinan Otentik}

Aspek-aspek kepemimpinan otentik menurut Walumbwa, dkk 2008 diantaranya adalah sebagai berikut:

\section{a. Self Awarenes (Kesadaran Diri)}

Cara seseorang memandang dan memahami dirinya sendiri dari waktu kewaktu. Selain itu memahami akan kelebihan serta keruangan yang dimiliki. Hal ini mencakup mendapatkan wawasan mengenai dirinya berdasarkan sudut pandang orang lain (Kernis, 2003). Misalnya, seorang pemimpin menyadari bahwa ucapan dan tindakan tertentu dapat memberikan dampak bagi orang lain.

b. Relational Transparency (Relasi yang Transparan)

Persepsi pengikut terhadap perilaku pemimpin yang menampilkan dirinya secara -aslill dalam berinteraksi dengan orang lain, bukan pencitraan diri maupun pendistorsian diri. Misalnya, seorang pemimpin yang menampilkan sifatnya secara -originall dan tanpa dibuat-buat dengan maksut pencitraan (Kernis, 2003). Contoh, seorang pemimpin mengakui kesalahan yang telah dilakukannya.

c. Balanced Processing (pemrosesan yang seimbang)

Menunjukkan seorang pemimpin yang secara obyektif menganalisis semua informasi dan data yang ada secara relevan sebelum mengambil keputusan. Misal, seorang pemimpin ketika akan mengambil keputusan melihat dari berbagai sudut pandang serta menganalisis berbagai informasi terlebih dahulu (Gardner, Avolio, Luthans, dkk., 2005). Contoh, seorang pemimpin akan memperhatikan dengan seksama sudut pandang yang berbeda sebelum mengambil keputusan.

d. Internalized Moral Perspective (Perspektif Moralyang Diinternalisasi)

Merupakan gambaran bawahan terhadap atasan mengenai internalisasi dan regulasi diri, artinya adalah apabila atasan membuat suatu keputusan maka keputusan tersebut sesuai dengan regulasi diri atau tidak bertentangan dengan nilai moral yang dianutnya. Misalnya, pemimpin yang ketika mengambil keputusan berdasarkan standar nilai moral/etika yang telah ditetapkan (Ryan \& Deci, 2003). Contoh, seorang pemimpin mengambil keputusan berdasarkan nilai-nilai hidup yang diyakininya.

MenurutMazutis

mengemukakan indikator kepemimpinan otentik yaitu sebagai berikut:

a. Kewaspadaan Diri

Meningkatnya kewaspadaan diri adalah faktorperkembangan penting bagi pemimpin otentik. Denganmengenali diri sendiri, pemimpin otentik memiliki pemahaman yang kuat seputar kediriannya sehingga menjadi pedoman mereka baik dalam setiap proses pengambilan keputusan maupun dalam perilaku kesehariannya. Kewaspadaan diri juga melibatkan kesadaran akan kekuatan diri, kelemahan diri, sebagai unsur-unsur yang saling bertolak belakang yang ada padasetiap manusia.

b. Nilai

Pemimpin otentik akan melawan setiap tuntutan situasional serta sosial yang dianggap mencoba melemahkan nilai-nilai yang mereka miliki. Nilai juga menyediakan dasar bagi tindakan pemimpin dalam upaya penyesuaian mereka atas kebutuhan komunitas yang mereka pimpin. Nilai dipelajari lewat proses sosialisasi.

c. Emosi 
Pemimpin otentik juga memiliki kewaspadaan diri yang bersifat emosional. Semakin tinggi kecerdasan emosional seseorang, semakin waspada mereka atas emosi tersebut sehingga dapat memahami pengaruhnya atas proses kognitif dan kemampuan pembuatan keputusannya. Kesadaran diri seputar dimensi emosi seseorang merupakan prediktor kunci untuk membangun kepemimpinaan yang efektif.

d. Tujuan

Pemimpin otentik berorientasi pada masa depan. Mereka secara terus-menerus berupaya mengembangkan baik dirinya maupun para pengikutnya. Tindakan pemimpin otentik diarahkan oleh motifmotif untuk menyempurnakan dirinya.

\section{Kepemimpinan Otentik dalam Organisasi}

Mengutip Munir (2018), para ahli kepemimpinan di sekolah bisnis Harvard pernah melakukan interviu kepada 172 pemimpin yang dipandang memenuhi kriteria sebagai pemimpin yang otentik. Kesimpulannya, otentisitas tidak bisa dibentuk seketika, melainkan melalui proses praktik kepemimpinan yang melalui pergulatan mengatasi berbagai persoalan dan tantangan.Hasil studi mengenai kepemimpinan otentik menunjukkan bahwa proses terbentuknya kepemimpinan otentik merupakan proses belajar, bertumbuh dan berkembang dari si pemimpin tersebut.

Lebih lanjut Munir (2018), menjelaskan dalam proses tersebut, kandidat pemimpin otentik mengintegrasikan pengalaman-pengalamannya dalam sebuah proses konstruksi diri yang membuatnya memandang situasi dan kondisi sekitarnya dengan pemahaman atau makna yang berbeda. Dalam menjalankan tugas-tugasnya sebagai pemimpin, mereka juga mengembangkan pemahaman atas dirinya dan mengalami proses berdamai dengan dirinya. Sehingga terbentuklah otentisitas dirinya.

Hasil studi juga menunjukkan pemimpin otentik melakukan refleksi dan introspeksi setiap hari. Hal ini dilakukan secara formal dengan meditasi, berdoa, salat, atau ritual lainnya, atau sekedar duduk sebentar melakukan perenungan. Kuncinya ialah mereka keluar sebentar dari rutinitas kesibukan, termasuk melepaskan diri dari gawai dan interaksi dengan media sosial $(F B$, twitter, $W A$, dst), atau baca berita, untuk bisa melakukan refleksi diri. Intinya mereka menunjukkan bagaimana mereka bisa hidup serasi dengan kesibukan kerjanya, tanpa terhanyut oleh kesibukan tersebut (Munir, 2018).

Kemudian Munir

menjelasakan bahwa para pemimpin otentik senantiasa mencari umpan-balik yang apa adanya, jujur dari kolega, teman-teman, maupun anak buah tentang dirinya dan praktik kepemimpinannya. Mereka mengakui bahwa hal yang sulit ialah untuk mendapatkan umpan-balik tentang "bagaimana orang-orang melihat dirinya", yang harus dia bedakan dengan "bagaimana aku ingin dilihat, dinilai oleh orang-orang". Untuk itu dia mengamati "real-time feedback", mencatat respons langsung saat dia berkomunikasi dengan orang-orang, bawahannya.

Pemimpin otentik selalu berupaya memahami tujuan kepemimpinannya, sehingga dia bisa mengajak orang-orang di sekitarnya untuk menuju tujuan bersama. Tujuan bersama memungkinkannya mengenali potensi dan keunikan masingmasing orang yang dia pimpin. Dengan begitu dia dapat menyerasikan keunikan dan peran tiap orang dalam mencapai tujuan bersama. Aspek ini jauh lebih penting untuk memfokuskan semua orang berkontribusi mencapai tujuan, daripada memfokuskan mereka pada sekedar ukuran kuantitatif seperti jumlah uang, ketenaran, dan kekuasaan. Walau tentu saja ukuran kinerja tersebut juga perlu.

Proses-proses yang dilewati oleh pemimpin otentik menjadikan mereka terampil dalam merangkai, memadukan gaya kepemimpinannya dengan audiensnya, sejalan dengan situasi, dan kesiapan dari sekitar untuk menerima perbedaan pendekatan. Sekali waktu ada situasi di mana seorang pemimpin harus membuat 
keputusan sulit yang membuat kolega atau bawahannya tidak nyaman, dan mereka perlu tampil tegar, tegas, dan berani memberi umpan balik yang tajam. Pada kesempatan lain, dia perlu tampil menginspirasi, sebagai coach yang baik, dan membangun konsensus.

$\begin{array}{clr}\text { Sebagai } & \text { pemimpin } & \text { mereka } \\ \text { mendapatkan } & \text { pengalaman } & \text { dan }\end{array}$
mengembangkan kesadaran diri yang lebih luas, mereka lebih terlatih, mahir dalam mengadaptasikan gaya kepemimpinannya, tanpa kehilangan ciri karakternya sendiri. Otentisitas pada level lebih dalam juga terkait dengan transparansi dan komunikasi yang jujur, berdamai dengan paradoks, dan mencari kebenaran (dalam Munir, 2018).

Shamir \& Eilam (2005) melakukan kajian tentang pengembangan kepemimpinan otentik melalui refleksi terhadap perjalanan hidup pemimpin (life story). Pengembangan kepemimpinan otentik tersebut memiliki empat komponen. Pertama, pengembangan identitas pemimpin sebagai komponen utama dari konsep diri individu (Development of a leader identity as a central component of the person's selfconcept). Kedua, Pengembangan pengetahuan diri dan kejelasan konsep diri, termasuk kejelasan tentang nilai-nilai dan keyakinan (Development of self-knowledge and self-concept clarity, including clarity about values and convictions). Ketiga, pengembangan tujuan hidup yang sesuai dengan konsep diri (Development of goals that are concordant with the self-concept). Keempat, peningkatan konsistensi antara perilaku dengan konsep diri pemimpin (Increasing self-expressive behavior, namely consistency between leader behaviors and the leader's self-concept).

\section{Kesimpulan}

1. Kepemimpinan otentik adalah seorang pemimpin yang mampu jujur pada dirinya sendiri dan para pengikutnya. Pemimpin otentik harus menyadari akan dirinya sendiri dan mampu menumbuhkan kesadaran diri para karyawannya untuk bekerja secara maksimal.
2. Walumbwa, dkk (2008), menyatakan terdapat empat aspek kepemimpinan otentik, yaitu self-awareness, moral perspective, balanced processing, dan relational transparency.

3. Kepemimpinan otentik dapat dikembangkan namun membutuhkan waktu yang tidak singkat untuk membangunnya.

\section{REFERENSI}

Andiyasari, A,. Pitaloka, A. 2017 Persepsi Kepemimpinan Otentik dan Work Engagement pada Generasi X dan Y di Indonesia.

Budiharto, Sus. Pengembangan Kepemimpinan Otentik (Konseptualisasi, Pengukuran, dan Implemetasinya dalam Organisasi. Makalah, diakses 03 April 2019.

Hassan, A., Ahmed, F. (2011). Authentic leadership, trust and work engagement. International Journal of Social, Behavioral, Educational, Economic, Business and Industrial Engineering, 5 (8), 1036 - 1042.

Illies, R. M., \& Nahrgang, J. D. 2005. Authentic leadership and eudaemonic well-being: understanding leader-follower outcomes. The Leadership Quarterly, Vol, 16: 373394.

Jatmika, D. 2016. Kepemimpinan Otentik (Authentic Leadership) [online]. Tersedia:

http://buletin.kpin.org/index.php/arsi p-artikel/143-kepemimpinan-otentikauthentic-leadership.

Kruse, Kevin (2013), What Is Authentic Leadership?

https://www.forbes.com/sites/kevinkr use/2013/05/12/what-is-authenticleadership/\#2953647edef7

Mazutis, Daina. 2011."Authentic Leadership" dalam W. Glenn Rowe and Laura Guerrero, eds., Cases in Leadership. Thousand Oaks. California: Sage Publications.

Munir, N.S.https://ppmmanajemen.ac.id/id_ID/blog/artikel- 
78 Jurnal Al-Qalb, Jilid 10, Nomor 1, Maret 2019, hlm. 71-78

manajemen-18/post/pemimpin-

otentik-dibangun-melalui-

pengalaman-

1591.SWAonline 6/08/2018

Penger, S., \& Černea, M. (2014). Authentic leadership, employees' job satisfaction, and workengagement: a hierarchical linear modelling approach. Economic ResearchEkonomska Istraživanja, 2014 Vol. 27, No. 1, 508-526).

Shamir, Boas, and Galit Eilam. "What's Your Story? A Life-Stories
Approach to Authentic leadership Development." JournalThe Leadership Quarterly 16 (2005).

Walumbwa, F.O., Avolio, B.J., Gardner, W.L., Wernsing, T.S. \& Peterson, S.J. 2008. Authenticleadership: Development and validation of $a$ theory-based measure. Journal of Management, 34(1), 89-126. doi:10.1177/0149206307308913

Yukl, G. 2015. Kepemimpinan dalam Organisasi. Alih Bahasa Ati Cahyani. Jakarta: Indeks. 